\title{
Sugarcane Burning - A Potential Cause of Disease in Affected Individuals of Households in Uitvlugt and Ogle, Guyana
}

\author{
Morisa Gamell ${ }^{1}$, Aminuddin Mohammad ${ }^{2}$, Kalyan Kumar Kakarla ${ }^{3}$, Abdullah Ansari ${ }^{4 *}$ \\ ${ }^{1}$ Department of Biology, University of Guyana, Georgetown, Guyana \\ ${ }^{2}$ Assistant Professor, Department of Biochemistry, Texila American University, Lot 24-42, Plantation, Providence, East Bank Demerara, Georgetown, \\ Guyana \\ ${ }^{3}$ Professor \& Unit Head, Department of Biochemistry, Texila American University, Lot 24-42, Plantation, Providence, East Bank Demerara, \\ Georgetown, Guyana \\ ${ }^{4}$ Department of Biology, University of Guyana, Georgetown, Guyana
}

DOI: $10.36348 /$ sijb.2020.v03i09.001 $\quad$ | Received: 03.09.2020 | Accepted: 13.09.2020 | Published: 19.09 .2020

*Corresponding author: Dr. Abdullah Ansari

\section{Abstract}

The sugar industry is one of the earliest and most successful users of biomass for commercial energy production. Sugar cane harvesting by burning is an environmental health issue due to respiratory effects of smoke. The present study is to investigate the current situation concerning sugarcane burning as a potential cause of disease in affected individuals of households in Uitvlugt and Ogle, Guyana. A total of 50 households investigated at each study site, results showed that there were no chronically exposed households to sugarcane smoke and soot for the study site used as the control when compared to the study site at Ogle and Uitvlugt. Out of 50 a total of fifteen households investigated at parfait harmony which reported the presence of respiratory disease within their households; asthma and bronchitis was the most commonly reported. Ogle showed the least number of nine, and Uitvlugt showed the highest number of twenty three, both with asthma being the most common. Uitvlugt showed a complete total of fifty households reporting dermatological problems, they all complained of unbearable itching when exposed to the sugarcane soot. Ogle reported one incidence of this, and Recht door zee (control site) reported nil. In the case of cardiovascular problems, Uitvlugt showed the highest incidence of thirty seven, and both Ogle and Recht door zee (control site) showed five. Cancer was reported by nine households in Uitvlugt, two in Recht door zee (control site), and nil in Ogle. To conclude, there is a high prevalence of chronic exposure to sugarcane smoke and soot in Uitvlugt, and negligible prevalence of chronic exposure to sugarcane smoke and soot in Ogle. There is a high prevalence of these diseases in Uitvlugt, followed substantially less by Recht door zee (control site), and Ogle having a very small prevalence.

Keywords: Sugarcane; respiratory diseases, cardiovascular problems, Cancer.

Copyright @ 2020: This is an open-access article distributed under the terms of the Creative Commons Attribution license which permits unrestricted use, distribution, and reproduction in any medium for non-commercial use (NonCommercial, or CC-BY-NC) provided the original author and source are credited.

\section{INTRODUCTION}

Sugarcane is a giant tropical grass grown as stout, jointed, fibrous stalk taken from setts or cuttings and after planting. The burning practice for sugarcane residues varies worldwide [1]. However, the burning of sugarcane straw is responsible for the emission of large quantities of pollutants that contribute to adverse effects on the health of workers and populations of cities near the burning regions [2]. Burning of sugarcane generates a huge amount of air pollutants such as aerosols, fine $\left(\mathrm{PM}_{2,5}\right)$ and coarse $\left(\mathrm{PM}_{10}\right)$ particulate matter, gases such as carbon monoxide $(\mathrm{CO})$ and carbon dioxide $\left(\mathrm{CO}_{2}\right)$, aldehydes (acrolein, formaldehyde), methane $\left(\mathrm{CH}_{4}\right)$, nitrogen oxides (NOx), nitrous oxide $\left(\mathrm{N}_{2} \mathrm{O}\right)$, other hydrocarbons and polycyclic aromatic hydrocarbons (PAHs) [3]. Once in the atmosphere, some of these gases - such as methane, $\mathrm{NO}_{2}$ and hydrocarbons - may produce secondary pollutants such as ozone $\left(\mathrm{O}_{3}\right)$, through photochemical reaction

The sugarcane harvesting is one of the earliest and most successful users of biomass for commercial energy production. Additionally, with sugar being the main produce, some other products that can be derived from sugarcane include; Ethanol, Molasses, Bagasse, Boller Ash and Filter Mud, Co-generation of electricity, and Dunder [4].

Understandably, scientific literature regarding the effects of sugarcane burning on health is still very limited. There are studies on health effects caused by biomass burning in general, which at times mention 
sugarcane. There are only a few published studies to date that examine the health effects of sugar cane burning and none examining health effects. Several studies showed that the burning sugarcane residues release many particles, which have toxic chemical compounds, and as such the micro-particulate matter can induce alterations in the respiratory system [5].

Besides the traditional respiratory problems, burning of fields is also causing cancer and cardiovascular diseases. This is interesting because foreign research conducted over the last decade reinforce the arguments that seek to ban the sugarcane burning practice, usually performed between the months from May to November in the harvests of sugar and alcohol producers [6].

Therefore, the present study is to investigate the current situation concerning sugarcane burning as a potential cause of disease in affected individuals of households in Uitvlugt and Ogle, Guyana. Its objective is to determine whether or not sugarcane burning is a potential cause of disease in chronically exposed individuals, and to suggest questions for future research.

\section{MATERIALS AND METHODS}

The present study was conducted using two known sites that are exposed to sugarcane burning, it's smoke and it's soot (Uitvlugt, W.C.D and Ogle, E.C.D) and another site that is not exposed to sugarcane burning, it's smoke or its soot (Recht Door Zee, W.B.D) which will be used as a control.
The other two sites are chosen because of their close proximity to nearby sugarcane fields and the day to day winds blowing in their directions which indicated their exposure to the sugarcane smoke and soot on its occasions of burning. The study site chosen at Uitvlugt is the area in closest proximity to Guyana Sugar Corporation INC Uitvlugt and Leonora Estate. The households targeted were those at the end of that estate road which starts from the public road to just about a mile down. And the second being Ogle cane fields, were those households to the left, down the airstrip road, carrying just the same distance down that road

The main tool for conducting this research was of personally issued questionnaires, while informed consent was sought from all who accepted to participate. The questionnaire consisted of ten (10) questions of simple terms which are included in the appendix of this report.

\section{Data Analysis}

The data collected were carefully quantified based on households investigated at each study site, the raw data was recorded in the order of household and study site investigated, it was then organized using tables, and interpreted using basic statistical tools such as the histogram to represent the number of investigated households that were chronically exposed to sugarcane smoke and soot in each study site.

\section{Changes that Occurred During Data Collection}

There was no significant change in the data collection process besides the fact that it took two weeks longer to get everything in order.

\section{RESULTS AND DISCUSSION}

Table-1: Showing the number of households that are chronically exposed to sugarcane smoke and soot, from the results obtained from each study site

\begin{tabular}{|l|l|}
\hline Study site & Households chronically exposed \\
\hline Recht door zee (Control) & 0 \\
\hline Ogle & 3 \\
\hline Uitvlugt & 50 \\
\hline
\end{tabular}

This table shows the total number of investigated households that are chronically exposed to sugarcane smoke and soot from the burning of sugarcane between the months of May and November of every year, at each study site, with the exception of Recht door zee (control site), which was used as the control. Of the total fifty households investigated at each study site, results obtained showed that there were no chronically exposed households to sugarcane smoke and soot for the study site used as the control. It also indicated that there was a small number of three households that were chronically exposed to sugarcane smoke and soot within the study site at Ogle, and it showed that of the total fifty households investigated at Uitvlugt, the entire fifty households were being chronically exposed, with some being affected more substantially than others. 


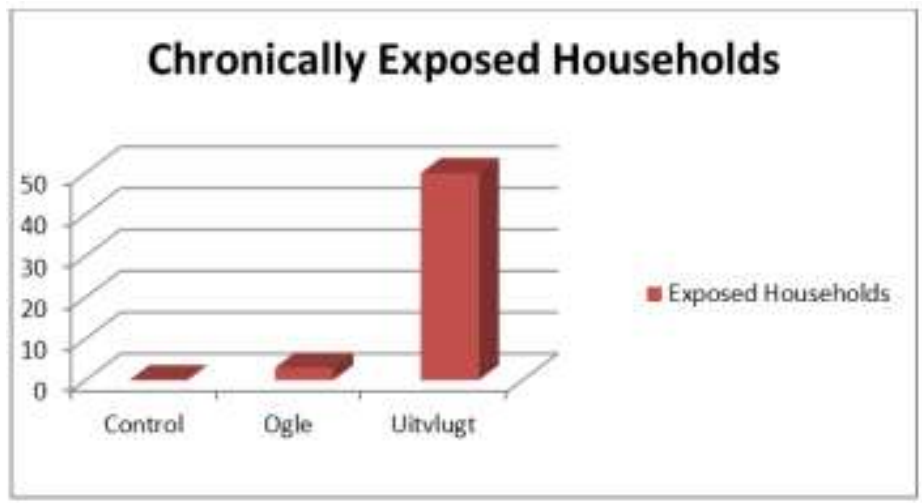

Fig-1: Showing the number of households that are chronically exposed to Sugarcane smoke and soot

The figure depicts the results obtained of the total number of households that are chronically exposed to sugarcane smoke and soot. There's a clear depiction that Uitvlugt had the highest number of chronically exposed households with the full total of the fifty households investigated. It also clearly shows that Recht door zee (Control site) had the lowest of nil households affected by the sugarcane smoke and soot from the total of fifty households investigated.

Table-2: Showing the number of investigated households that reported an incidence of respiratory, dermatological, cardiovascular, and cancer disease in each study site

\begin{tabular}{|l|l|l|l|l|}
\hline Study site & Respiratory & Dermatological & Cardiovascular & Cancer \\
\hline Recht door zee (Control) & 15 & 0 & 5 & 2 \\
\hline Ogle & 9 & 1 & 5 & 0 \\
\hline Uitvlugt & 23 & 50 & 37 & 9 \\
\hline
\end{tabular}

This table shows the results obtained from each study site indicating the number of households investigated who reported the presence of disease in their households. Some of the households showing the incidence of disease indicated the presence of more than one disease in the household. In the case of respiratory diseases, the most common reported was asthma and occasional shortness of breath upon exposure to the sugarcane smoke and soot by the individuals of the affected households.

There were a total of fifteen (15) households investigated at parfait harmony which reported the presence of respiratory disease within their households; asthma and bronchitis was the most commonly reported. Ogle showed the least number of nine (9), and Uitvlugt showed the highest number of twenty three
(23), both with asthma being the most common. Uitvlugt showed a complete total of fifty (50) households reporting dermatological problems, they all complained of unbearable itching when exposed to the sugarcane soot. Ogle reported one incidence of this, and Recht door zee (control site) reported nil.

In the case of cardiovascular problems, Uitvlugt showed the highest incidence of thirty seven (37), and both Ogle and Recht door zee (control site) showed five (5). They all indicated similar cardiovascular problems with hypertension being the most common. Cancer was reported by nine (9) households in Uitvlugt, two (2) in Recht door zee (control site), and nil in Ogle. The most common reported was breast cancer.

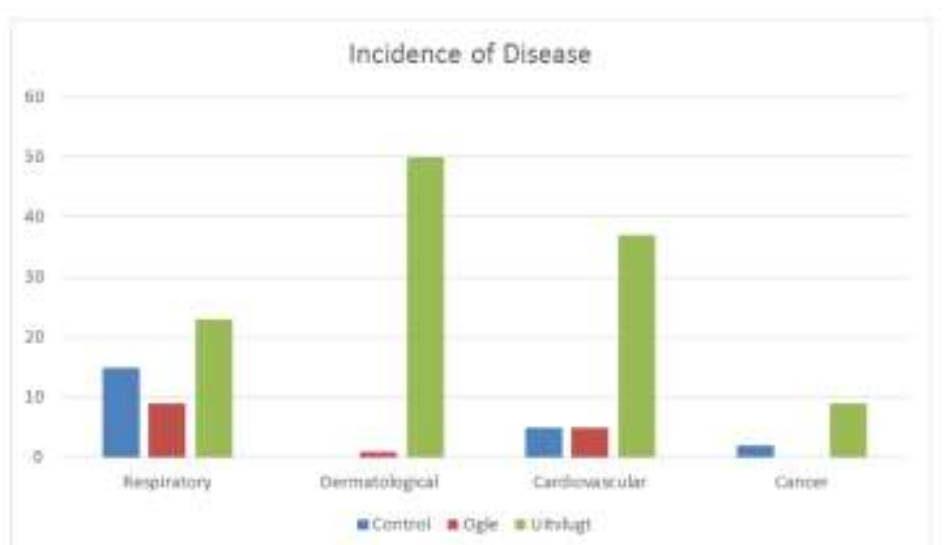

Fig-2: Shows the incidence of respiratory, dermatological, cardiovascular, and cancer disease in investigated households of each study site 
The figure clearly depicts the incidence of respiratory, dermatological, cardiovascular, and cancer disease in investigated households in each study site.
Uitvlugt showed the highest incidence for all the diseases while Ogle shows the lowest incidence.

Table-3: Showing the total number of households with an incidence of disease.

\begin{tabular}{|l|l|}
\hline Study site & Households showing incidence of disease \\
\hline Recht door zee (Control) & 19 \\
\hline Ogle & 12 \\
\hline Uitvlugt & 50 \\
\hline
\end{tabular}

The table shows the results obtained from each study site indicating the total number of households that reported the presence of disease. The results shows that of the total fifty (50) households investigated, there was a total of nineteen (19) households in Recht door zee (control site) that reported the incidence of disease, there was also a total of twelve (12) households in Ogle, and for Uitvlugt the full total of fifty (50) households reported disease.

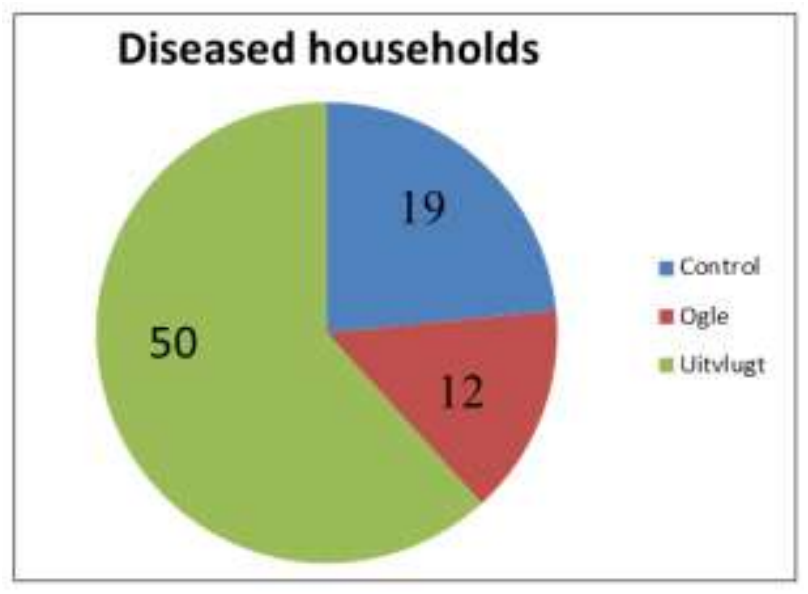

Fig-3: Showing the total number of households investigated that reported an incidence of disease

The pie chart clearly depicts total number of households investigated that reported an incidence of disease and the difference between the total numbers of households that reported the incidence of disease. Uitvlugt recorded the highest of fifty (50), and Ogle reported the lowest with a total of twelve (12).

\section{DISCUSSION}

Burning of sugarcane residues is a common practice all over the world, especially in developing countries. And as such, the impact of biomass and fossil fuel burning is felt throughout the world, and although studies have documented the impact of fossil fuel air pollution on health, there is a scarcity of information on biomass burning [7].

In the sugarcane burning process, the field is set fire to and the leaves are burned off of the stalks. About $80 \%$ of the waste materials, including straw, the tops, and green and dry leaves, are burned off. These components constitute about $25 \%$ of the entire sugar cane stalk (8).

Cancado et al., [7], analyzed the influence of emissions from burning sugarcane on the respiratory system during almost 1 year in the city of Piracicaba in southest Brazil, where consistent samples of inhalable particles were collected, separated into fine and coarse particulate mode, and analyzed for black carbon and tracer elements. While at the same time they examined daily records of children $(<13$ years of age) and elderly people ( $>64$ years of age) admitted to the hospital because of respiratory diseases. Analyses were carried out for the entire period, as well as for burning and nonburning periods. When they compared periods, the effects during the burning period were much higher than the effects during non-burning period. It was concluded that elements generated from sugar cane burning were those most associated with both child and elderly respiratory admissions. Their results showed the adverse impact of sugar cane burning emissions on the health of the population.

In the present study, to establish a link between the prevalence of chronic exposure to sugarcane smoke and soot, and the potential diseases that members of the affected households of each study site have developed or would be prone to developing in the future.

Of the total fifty households chronically exposed in Utivlugt, all fifty of them reported the incidence of one or more of these diseases in the investigated households. Although Recht door zee 
(control site) was not exposed to sugarcane smoke and soot, there was still disease present in nineteen households, and Ogle with very limited exposure had a value of twelve households with incidence of disease. However, the numbers speak for themselves and it can be stated that a there is a link between the prevalence of chronic exposure to sugarcane smoke and soot, and the potential diseases that members of the affected households have developed or would be prone to developing in the future.

Results obtained and analyzed, reported a low incidence of disease overall for the Ogle study site, this is assumed to be as a result of the quality of the fresh air coming in from the ocean that's constantly circulating through the wide open spaces within the area. That, and the limited exposure to the sugarcane burning that's done on a regular between the months of May to November of every year is liable to contribute to the better overall health of the individuals of the total households investigated.

According Isaude, the soot emitted by the burning of biomass, especially fine particles (known as PM10, less than 10 microns) and ultrafine (or PM 2.5, smaller than 2.5 micrometers) contains substances carcinogenic and can also cause cardiovascular disorders [9].

Moreover, resulting air pollutants from sugar cane burning include acidic fine particles, such as secondary nitrates and sulfates and carbon compounds [10]. Carbon monoxide and methane react with atmospheric hydroxyl radicals, which decreases oxidation efficiency, nitric oxide and hydrocarbons produce high ozone concentrations during the dry season. One study carried out showed that burning season produced significantly higher concentrations of HCOO-, CH3COO-, C2O2-4, SO2-4, NO-3, , K+, $\mathrm{NH}+4, \mathrm{Mg} 2+$ and $\mathrm{Ca}+$, with the only tested species unaffected being $\mathrm{Cl}-$ and $\mathrm{Na}+$. Results of some research shows that sugar cane fires contribute to about $60 \%$ of fine particle mode mass, $64 \%$ of the black carbon mass, and $25 \%$ of the course particle mode mass present in urban areas adjacent to cane fields [11].

A study, done by researcher Mary Rose Marchi, Institute of Chemistry, Unesp in Araraquara, a city surrounded by cultivation of cane sugar, and other colleagues investigated the organic composition of particles from burning. Her suspicion was that the sugarcane soot contained PAHs [polycyclic aromatic hydrocarbons - chemical compounds with known mutagenic and carcinogenic], since they are produced during incomplete combustion of organic material. Confirmed the hypothesis, the researcher selected 17 of these aromatic, identified as priority pollutants by environmental agencies internationally, and initiated a series of studies on the sugarcane soot [12].
Despite their restrictions and cautious conclusions; studies analyzed indicates health risks in adverse atmospheric conditions, caused by sugarcane straw burning. These risks can be higher among children, elderly people and asthmatics, mainly resulting in higher demand for health care [13].

On the other hand, with Uitvlugt showing the incidence with the highest number of the households being affected by disease, the complete fifty, and that same fifty households all being chronically exposed to the sugarcane smoke and soot, it is safe to say that the hypothesis "Sugarcane burning is a potential cause of disease in individuals of affected households" is proven to be correct and true. To conclude, there is a high prevalence of chronic exposure to sugarcane smoke and soot in Uitvlugt, and negligible prevalence of chronic exposure to sugarcane smoke and soot in Ogle. There is a high prevalence of these diseases in Uitvlugt, followed substantially less by Recht door zee (control site), and Ogle having a very small prevalence.

\section{REFERENCES}

1. de Aquino, G. S., de Conti Medina, C., da Costa, D. C., Shahab, M., \& Santiago, A. D. (2017). Sugarcane straw management and its impact on production and development of ratoons. Industrial Crops and Products, 102, 58-64.

2. Mazzoli-Rocha, F., Magalhaes, C. B., Malm, O., Saldiva, P. H. N., Zin, W. A., \& Faffe, D. S. (2008). Comparative respiratory toxicity of particles produced by traffic and sugar cane burning. Environmental research, 108(1), 35-41.

3. Arbex, M. A., Cançado, J. E., Pereira, L. A., Braga, A. L., \& Saldiva, P. H. (2004). Burning biomass and its effect on health. J Bras Pneumol, 30(2):158-175.

4. Paturau, J. M. (1986). Alternative uses of sugarcane and its byproducts in agroindustries. In: Sansoucy, R., Aarts, G., \& Prestos, T. R. editors. Sugarcane as Feed. Rome: FAO.

5. Arbex, M. A., Martins, L. C., de Oliveira, R. C., Pereira, L. A. A., Arbex, F. F., Cançado, J. E. D., ... \& Braga, A. L. F. (2007). Air pollution from biomass burning and asthma hospital admissions in a sugar cane plantation area in Brazil. Journal of Epidemiology \& Community Health,61(5), 395-400.

6. Brook, R. D., Rajagopalan, S., Pope III, C. A., Brook, J. R., Bhatnagar, A., Diez-Roux, A. V., ... \& Peters, A. (2010). Particulate matter air pollution and cardiovascular disease: an update to the scientific statement from the American Heart Association. Circulation, 121(21), 2331-2378.

7. Cançado, J. E., Saldiva, P. H., Pereira, L. A., Lara, L. B., Artaxo, P., Martinelli, L. A., ... \& Braga, A. L. (2006). The impact of sugar cane-burning emissions on the respiratory system of children and the elderly. Environmental health perspectives, 114(5), 725-729. 
8. Rípoli, T. C. C., Molina Jr, W. F., \& Rípoli, M. L. C. (2000). Energy potential of sugar cane biomass in Brazil. Scientia Agricola, 57(4), 677-681.

9. Barbosa, C. M. G., Terra-Filho, M., de Albuquerque, A. L. P., Di Giorgi, D., Grupi, C., Negrao, C. E., ... \& Braga, A. L. F. (2012). Burnt sugarcane harvesting-cardiovascular effects on a group of healthy workers, Brazil. PloS one, 7(9), e46142.

10. Allen, A. G., Cardoso, A. A., \& Da Rocha, G. O. (2004). Influence of sugar cane burning on aerosol soluble ion composition in Southeastern Brazil. Atmospheric Environment, 38(30), 50255038.
11. Lara, L. L., Artaxo, P., Martinelli, L. A., Camargo, P. B., Victoria, R. L., \& Ferraz, E. S. B. (2005). Properties of aerosols from sugar-cane burning emissions in Southeastern Brazil. Atmospheric environment, 39(26), 4627-4637.

12. Ibanhes, L. C., Santos, F. S. D., \& Boaretto, R. C. (2008). Poder Judiciário e saúde: o Ministério Público Federal e a atenção à Saúde Mental no município de São Paulo. BIS. Boletim do Instituto de Saúde (Impresso), (45), 7-9.

13. Ribeiro, A. P., Souza, E. R. D., Atie, S., Souza, A. C. D., \& Schilithz, A. O. (2008). A influência das quedas na qualidade de vida de idosos. Ciência \& Saúde Coletiva, 13, 1265-1273. 